\title{
Alpha-fetoprotein-producing early rectal carcinoma: a rare case report and review
}

\author{
Hiroyuki Anzai1", Shinsuke Kazama', Tomomichi Kiyomatsu', Takeshi Nishikawa', Toshiaki Tanaka', Junichiro Tanaka', \\ Keisuke Hata ${ }^{1}$, Kazushige Kawai ${ }^{1}$, Hironori Yamaguchi ${ }^{1}$, Hiroaki Nozawa' ${ }^{1}$, Takamitsu Kanazawa' ${ }^{1}$ Tetsuo Ushiku', \\ Soichiro Ishihara', Eiji Sunami ${ }^{1}$, Masashi Fukayama ${ }^{2}$ and Toshiaki Watanabe ${ }^{1}$
}

\begin{abstract}
Background: Alpha-fetoprotein (AFP)-producing rectal cancer is very rare, and this type of cancer frequently metastasizes to the liver with a poor prognosis. To date, only 11 cases of AFP-producing colorectal cancer have been reported.

Case presentation: A 41-year-old woman was first presented to the hospital for anal bleeding. An elevated tumor with a central shallow depression in the lower rectum was detected by colonoscopy. Transanal excision was performed, and the histology revealed adenocarcinoma. Further immunohistopathological examination revealed that the tumor was an AFP-producing adenocarcinoma of the rectum. Although local resection was performed 2 months before the diagnosis of AFP tumor, the serum AFP level was normal. The depth of the submucosal invasion was 5,000 $\mu \mathrm{m}$, and there was venous invasion. Also, no lymphatic invasion was detected. Therefore, additional surgical resection with lymph node dissection was conducted, and the patient underwent laparoscopic intersphincteric resection. No residual cancer was identified in the surgical specimens, and there was no evidence of lymph node metastasis. The patient was discharged 18 days postoperatively, and 12 months after the operation, there are no signs of recurrence.
\end{abstract}

Conclusion: To the best of our knowledge, this is the first case of an AFP-producing rectal cancer that was diagnosed at an early stage.

Keywords: Alpha-fetoprotein, Rectum, Early colon cancer, Adenocarcinoma

\section{Background}

Alpha-fetoprotein (AFP), a serum glycoprotein with a molecular weight of approximately $70 \mathrm{kDa}$, develops during gestation and is produced from fetal liver and yolk sac [1]. It was first described in 1963 by Abeleb et al. [2]. Immediately after birth, serum AFP levels are high, approximately $10,000 \mathrm{ng} / \mathrm{mL}$ but decrease rapidly, and by the second year of life and thereafter are less than $10 \mathrm{ng} / \mathrm{mL}$. Some tumors produce AFP and lead to an increase in serum AFP levels. Therefore, AFP is a useful tumor marker in the diagnosis of tumors, such as hepatocellular carcinomas, hepatoblastoma, and yolk sac tumors [3-5]. AFP-producing tumors have mainly been reported in organs originating from the foregut endoderm

\footnotetext{
* Correspondence: ANZAIH-SUR@h.u-tokyo.ac.jp

'Division of Surgical Oncology, Department of Surgery, Faculty of Medicine, The University of Tokyo, 7-3-1 Hongo, Bunkyo-ku, Tokyo 113-8655, Japan Full list of author information is available at the end of the article
}

[6]. The majority of AFP-producing cancers originate from the stomach, bile duct, and pancreas. However, AFPproducing colorectal cancer is extremely rare because the colorectum originates from the hindgut endoderm. Only 11 cases of AFP-producing colorectal cancer have been reported in English literature to date. Here, we report a case with early rectal cancer diagnosed as an AFP-producing tumor by immunohistochemistry. AFP-producing tumors have been reported to frequently metastasize to the liver and have a poor prognosis. However, the tumor in the present case was diagnosed at an early stage and no distant metastases were detected simultaneously [7-17]. To the best of our knowledge, this is the first case of an early diagnosis of an AFP-producing rectal cancer reported in English literature.

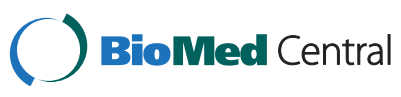

(c) 2015 Anzai et al.; licensee BioMed Central. This is an Open Access article distributed under the terms of the Creative Commons Attribution License (http://creativecommons.org/licenses/by/4.0), which permits unrestricted use, distribution, and reproduction in any medium, provided the original work is properly credited. The Creative Commons Public Domain Dedication waiver (http://creativecommons.org/publicdomain/zero/1.0/) applies to the data made available in this article, unless otherwise stated. 


\section{Case presentation}

A 41-year-old woman first noticed anal bleeding in December 2013. She had initially presented to a local hospital, and a colonoscopy was performed. Colonoscopy revealed an elevated tumor of approximately 15 $\mathrm{mm}$ in diameter with a central shallow depression in the lower rectum. It appeared similar to mucosal prolapse syndrome, and the histopathology of the biopsy specimen revealed no malignancy (Figure 1). Transanal excision of the elevated tumor was performed. The histopathological diagnosis of the tumor revealed a moderately differentiated adenocarcinoma. The patient was referred to our hospital for further investigation. Laboratory data investigations revealed normal serum hemoglobin. Tumor markers, such as carcinoembryonic antigen, carbohydrate antigen 19-9, and serum anti-p53 antibody, were within the normal ranges at $1.2 \mathrm{ng} / \mathrm{ml}$ (normal range 0 to $5.0 \mathrm{ng} / \mathrm{ml}$ ), $11 \mathrm{U} / \mathrm{ml}$ (normal range 0 to $37.0 \mathrm{U} / \mathrm{ml}$ ), and $0.40 \mathrm{U} / \mathrm{ml}$ (normal range 0 to $0.40 \mathrm{U} / \mathrm{ml}$ ), respectively. Although elevated AFP levels take several months to normalize after the resection, the serum levels of 2 months after resection were within normal limits at $2 \mathrm{ng} / \mathrm{ml}$ (normal range 0 to $10.0 \mathrm{ng} / \mathrm{ml}$ ). Abdominal computed tomography did not reveal liver metastasis, enlarged lymph nodes, or peritoneal metastasis, and the resected tumor was re-examined at our hospital. The schematic drawing of intraoperative situation is shown in Figure 2. Microscopically, the tumor comprised columnar neoplastic cells with clear cytoplasm showing tubular structure and focal solid growth by examination of the hematoxylin-eosin staining (Figure 3A). Most of the tumor was clear cell carcinoma, and the conventional adenocarcinoma present very focally (Figure 4). Immunohistochemistry using an anti-AFP antibody demonstrated diffused and strong positive staining of the cytoplasm of the neoplastic cells (Figure 3B). These results led to the diagnosis of AFPproducing adenocarcinoma of the rectum. The depth of the submucosal invasion was $5,000 \mu \mathrm{m}$, and there was a positive venous invasion (Figure $3 \mathrm{C}$ ). Both these findings were suggestive of possible lymph node metastasis; therefore, we advocated additional surgical resection with lymph node dissection. Furthermore, the patient underwent laparoscopic intersphincteric resection in March 2014. The histopathological report revealed no residual tumor in the surgical specimens and no lymph node metastasis. The patient was discharged 18 days postoperatively, and 12 months later, there are no signs of recurrence.

\section{Conclusions}

We report on a patient with AFP-producing rectal cancer diagnosed at an early stage. Although local resection was performed 2 months before the diagnosis of AFP tumor, the serum AFP levels of 2 months after the initial operation were normal. In Japanese literature, there are only two reported cases of AFP-producing colorectal disease detected in the early stages, which were T1 N0 and T2 N0 colorectal cancer, respectively[18,19]. AFPproducing cancer is defined by positively stained tumor of anti-AFP monoclonal antibody. Several reports describe that AFP-producing gastric cancer (AFP-GC) has an aggressive clinical course and poorer prognosis than AFP-negative GC. Interestingly, there are similarities with AFP-producing colorectal cancer and AFP-GC that it rapidly progresses and frequently metastasizes into the liver and show poor prognosis.

In present case, immunohistochemically evaluated glypican-3 expression, which is reported to be a sensitive marker for AFP-GC, was positive [20]. The immunohistochemical feature of present case was similar to AFP-GC. However, the histological characterization of AFP-producing colorectal cancer differs from AFPGC. Although the most common subtype of AFP-GC is poorly differentiated carcinoma, poorly to moderately differentiated carcinoma is commonly observed among AFP-producing colorectal cancer. Additionally AFP-producing colon cancer is extremely rare, with only 11 reported cases in English literature [7-17]. The clinicopathological findings of these cases are summarized in Table 1 . Of these 11 cases, 10 had elevated

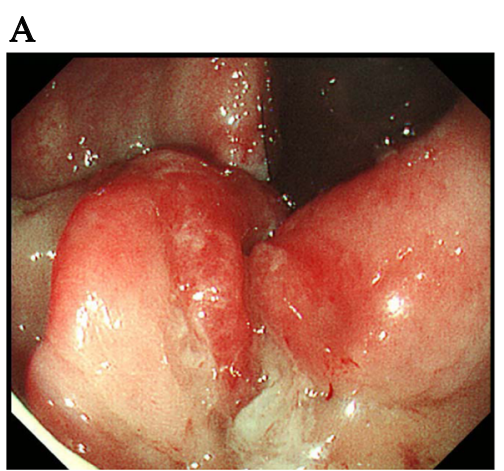

B

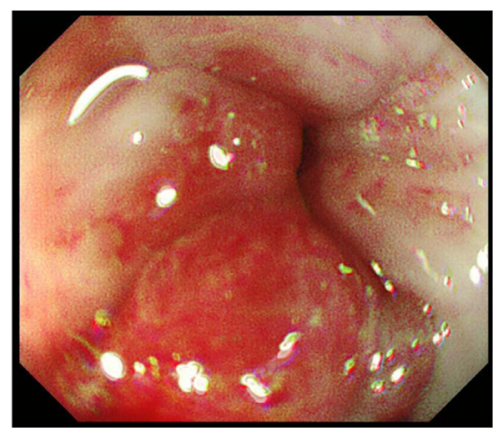

Figure 1 Colonoscopy findings. (A) Macroscopic evaluation by colonoscopy showed an elevated tumorous lesion in the lower rectum. A shallow depressed area can be seen at its center. (B) The surface of the elevated tumor showed redness. 
A

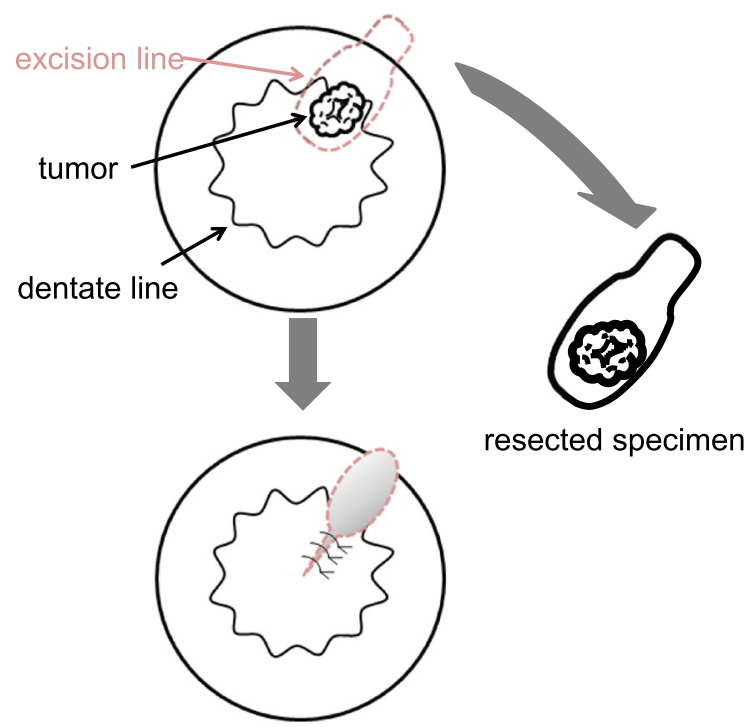

B

(6) (5) (4) (3) (2)(1)

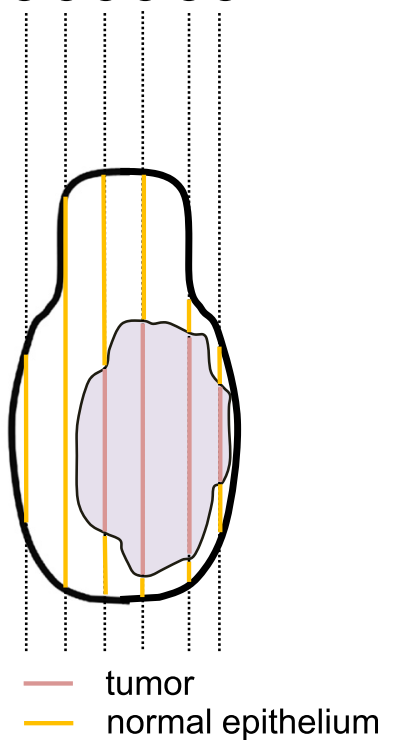

Figure 2 Schematic drawing of intraoperative situation. (A) Schematic drawing of intraoperative situation. (B) A schematic drawing of resected specimen.
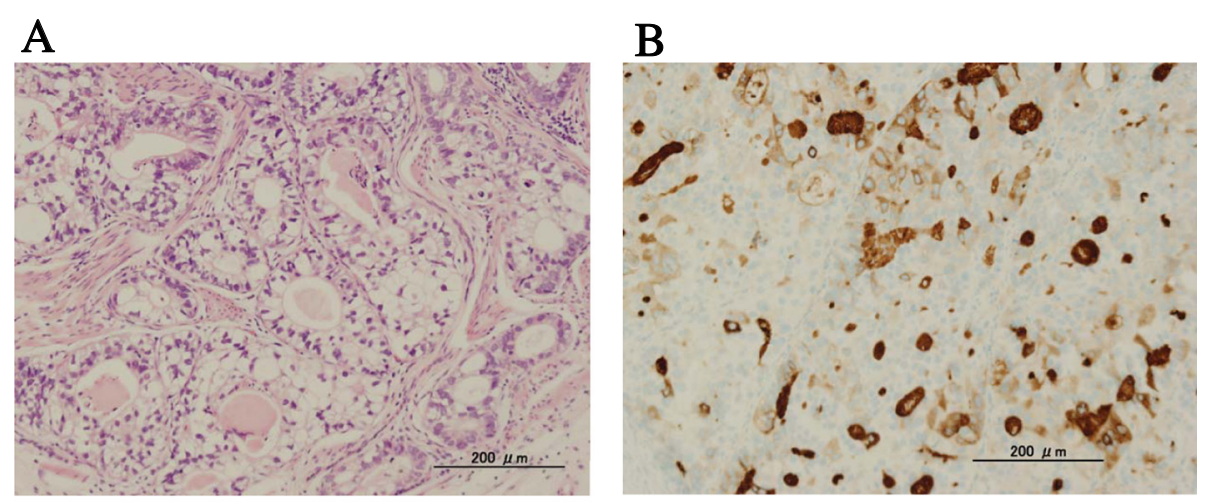

C

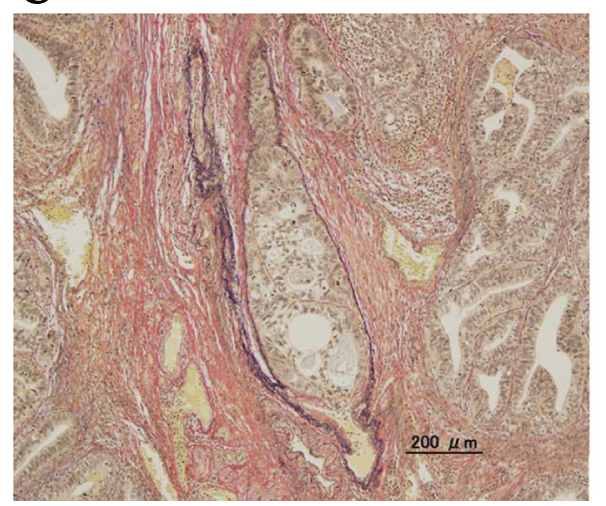

Figure 3 Microscopic findings. (A) Microscopic evaluation with hematoxylin-eosin staining of the tumor reveals columnar neoplastic cells with clear cytoplasm (original magnification, $\times 20$ ). (B) Immunohistochemical staining of the tumor using an antibody against AFP. Diffused and strong positive staining is observed in the cytoplasm of the neoplastic cells (original magnification, $\times 20$ ). (C) Elastic Van Gieson staining of the tumor reveals venous invasion by the adenocarcinoma (original magnification, $\times 25$ ). 


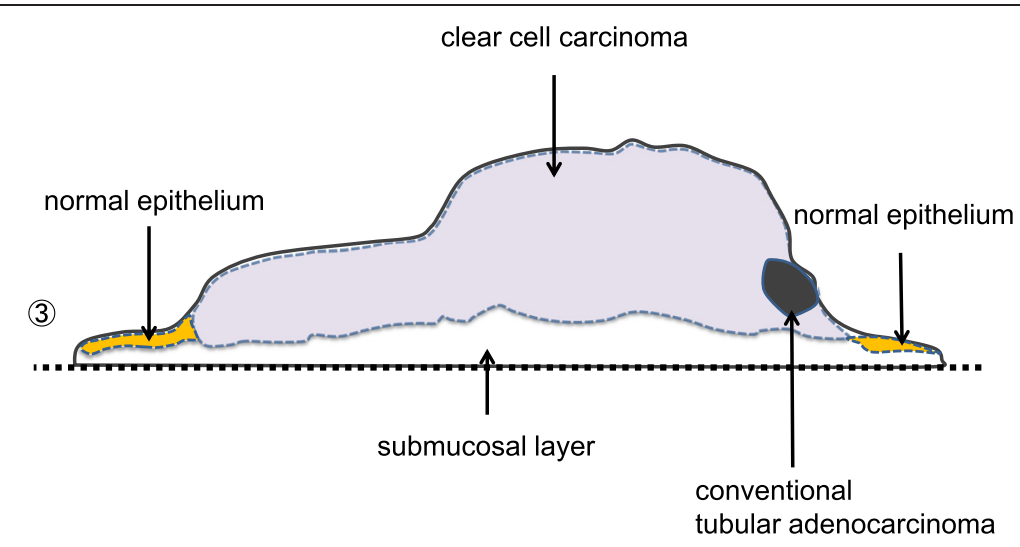

Figure 4 Histological mapping of cut surface (3).

serum levels of AFP. The rectum was the most common tumor site and almost all cases had extensive simultaneous liver metastasis. Of the 11 cases, 6 cases died of the primary AFP-producing tumor and 2 cases died of postoperative complications. In addition, although almost all reports demonstrate the poor prognosis of AFP-producing tumors, there was no distant metastasis or recurrence in the present case. Although there are several reports of an AFP-GC with features of hepatic differentiation, the mechanisms of AFPproducing rectal cancer or the hepatic differentiation remain obscure.

Several studies have demonstrated the histopathological factors that predict lymph node metastasis of T1 stage colorectal cancer. The rate of lymph node metastasis of submucosal cancer has been reported to be $6 \%$ to $12 \%$ [21]. The risk factors for lymph node metastasis in submucosal colorectal cancers include poor differentiation, lymphatic invasion, vascular invasion, deep submucosal invasion, or a positive resection margin [22-24]. In the present case, the risk factors of massive invasion and vascular invasion were detected, which led us to perform the additional surgery.

In conclusion, we report on an AFP-producing colon cancer diagnosed at an early stage, whereby early detection enabled a complete resection of the carcinoma. It is important to note that management of a patient with an elevated tumor with a shallow depression, even when no malignancy is detected, should include local excision for immunohistopathological analysis. Although serum AFP levels have been high in all previously reported cases, it is important to remember that serum AFP levels may not rise in the early stages of AFP-producing cancer. Further accumulation of data and investigation of AFP-producing colon cancer is necessary.

Table 1 Clinical features of reported cases of AFP-producing colorectal carcinomas

\begin{tabular}{|c|c|c|c|c|c|c|c|c|c|c|}
\hline Case & Author & $\begin{array}{l}\text { Age/ } \\
\text { gender }\end{array}$ & Location & $\begin{array}{l}\text { Pretherapy AFP } \\
\text { level }(\mathrm{ng} / \mathrm{ml})\end{array}$ & $\begin{array}{l}\text { Macroscopic } \\
\text { classification }\end{array}$ & $\begin{array}{l}\text { Depth of } \\
\text { invasion }\end{array}$ & $\begin{array}{l}\text { Lymph node } \\
\text { metastasis }\end{array}$ & $\begin{array}{l}\text { Pretherapy } \\
\text { Metastases }\end{array}$ & Histology & Prognosis \\
\hline 1 & Nakajima et al. [7] & $50 / \mathrm{M}$ & $\mathrm{R}$ & 3,018 & NS & Prostate & + & Liver/lung & Mod-por & $5 \mathrm{M}$ dead \\
\hline 2 & Yu et al. [8] & $54 / \mathrm{M}$ & $\mathrm{R}$ & 5,126 & Ulcerated & Serosal & + & Liver & Well & OM dead \\
\hline 3 & Sato et al. [9] & $43 / \mathrm{M}$ & $\mathrm{R}$ & 7,060 & Ulcerated & Extraserosal & + & Liver & Well-mod & 4M dead \\
\hline 4 & Hocking et al. [10] & $39 / F$ & $\mathrm{~S} / \mathrm{C}$ & 7,200 & NS & Perforation & + & Liver & a & $1 \mathrm{M}$ dead \\
\hline 5 & Kato et al. [11] & $75 / \mathrm{M}$ & C & 3,070 & Ulcerated & NS & + & No & Por & 4M dead \\
\hline 6 & Taguchi et al. [12] & $71 / \mathrm{M}$ & $\mathrm{R}$ & 220,000 & Ulcerated & Muscular & - & No & $\mathrm{b}$ & $12 \mathrm{M}$ dead \\
\hline 7 & Kurihara et al. [13] & $67 / M$ & $\mathrm{~T} / \mathrm{C}$ & 10,978 & Ulcerated & Serosal & + & Liver & Por & NS \\
\hline 8 & Ishikura et al. [14] & $48 / F$ & $\mathrm{~S} / \mathrm{C}$ & 6,600 & Ulcerated & Subserosal & NS & Liver & Well & $4 \mathrm{M}$ dead \\
\hline 9 & Lattes et al. [15] & $41 / \mathrm{M}$ & $\mathrm{R}$ & NS & Ulcerated & NS & + & Liver & Well-muc-sig & $12 \mathrm{M}$ alive \\
\hline 10 & Yachida et al. [16] & 59/M & $\mathrm{T} / \mathrm{C}$ & 12,873 & Ulcerated & Serosal & - & Liver & Well & 2M dead \\
\hline 11 & Fu et al. [17] & $71 / \mathrm{M}$ & $\mathrm{T} / \mathrm{C}$ & 318 & Ulcerated & Subserosal & - & No & Por & $5 Y$ alive \\
\hline 12 & Present case & $41 / F$ & $\mathrm{R}$ & 2 & Elevated & Submucosal & - & No & Mod-por & 2M alive \\
\hline
\end{tabular}

AFP = alpha-fetoprotein; NS = not stated; $\mathrm{C}=$ cecum; $\mathrm{S} / \mathrm{C}=$ sigmoid colon; $\mathrm{T} / \mathrm{C}=$ transverse colon; $\mathrm{R}=$ rectum; well = well differentiated adenocarcinoma; mod = moderately differentiated adenocarcinoma; por = poorly differentiated adenocarcinoma; muc = mucinous adenocarcinoma; sig = signet-cell-carcinoma; ${ }^{a}$ Adenocarcinoma showing hepatoid morphology; ${ }^{b}$ glandular differentiation consisted of columnar cancerous cells. 


\section{Consent}

Written informed consent was obtained from the patient for publication of this case report and accompanying images.

\section{Competing interests}

The authors declare that they have no competing interests.

\section{Authors' contributions}

HA and SK prepared the manuscript and the literature search; JT, TU, MF and $\mathrm{KK}$ reviewed and edited the manuscript; $\mathrm{HA}, \mathrm{HN}$ and $\mathrm{KH}$ corrected and revised the manuscript; HA, TKa, TW, SI and ES treated and observed the patient; TN, TT and TKi provided clinical images; HA, SK and HY performed data analysis. All authors read and approved of the final manuscript.

\section{Acknowledgements}

The authors wish to thank Tetsuo Ushiku for pathological diagnosis.

\section{Author details}

'Division of Surgical Oncology, Department of Surgery, Faculty of Medicine, The University of Tokyo, 7-3-1 Hongo, Bunkyo-ku, Tokyo 113-8655, Japan. ${ }^{2}$ Department of Pathology, The University of Tokyo, 7-3-1 Hongo, Bunkyo-ku, Tokyo 113-8655, Japan.

Received: 1 November 2014 Accepted: 24 April 2015

Published online: 12 May 2015

\section{References}

1. Bergstrand CG, Czar B. Demonstration of a new protein fraction in serum from the human fetus. Scand J Clin Lab Invest. 1956:8:174.

2. Abelev Gl, Perova SD, Khramkova NI, Postnikova ZA, Irlin IS. Production of embryonal alpha-globulin by transplantable mouse hepatomas. Transplantation. 1963;1:174-80.

3. Norgaard-Pedersen B, Albrechtsen R, Teilum G. Serum alpha-foetoprotein as a marker for endodermal sinus tumour (yolk sac tumour) or a vitelline component of "teratocarcinoma". Acta Pathol Microbiol Scand A. 1975:83:573-89.

4. O'Conor GT, Tatarinov YS, Abelev Gl, Uriel J. A collaborative study for the evaluation of a serologic test for primary liver cancer. Cancer. 1970;25:1091-8.

5. Smith CJ, Ajdukiewicz A, Kelleher PC. Concanavalin-A-affinity molecular heterogeneity of human hepatoma AFP and cord-serum AFP. Ann N Y Acad Sci. 1983:417:69-74.

6. McIntire KR, Waldmann TA, Moertel CG, Go VL. Serum alpha-fetoprotein in patients with neoplasms of the gastrointestinal tract. Cancer Res. 1975;35:991-6.

7. Nakajima T, Okazaki N, Morinaga S, Tsumuraya M, Shimosato Y, Saiki S. A case of alpha-fetoprotein-producing rectal carcinoma. Jpn J Clin Oncol. 1985:15:679-85.

8. Yu YY, Ogino T, Okada S. An alpha-fetoprotein-producing carcinoma of the rectum. Acta Pathol Jpn. 1992:42:684-7.

9. Sato Y, Sekine T, Ohwada S. Alpha-fetoprotein-producing rectal cancer: calculated tumor marker doubling time. J Surg Oncol. 1994;55:265-8.

10. Hocking GR, Shembrey M, Hay D, Ostor AG. Alpha-fetoprotein-producing adenocarcinoma of the sigmoid colon with possible hepatoid differentiation. Pathology. 1995;27:277-9.

11. Kato K, Matsuda M, Ingu A, Imai M, Kasai S, Mito M, et al. Colon cancer with a high serum alpha-fetoprotein level. Am J Gastroenterol. 1996;91:1045-6.

12. Taguchi J, Yano H, Sueda J, Yamaguchi R, Kojiro M, Shirouzu G, et al. alpha-Fetoprotein-producing rectal carcinoma - a case report. Kurume Med J. 1997:44:339-48.

13. Kurihara K, Konishi F, Kanazawa K, Fujii T, Saito K. Alpha-fetoprotein-producing carcinoma of the colon: report of a case. Surg Today. 1997;27:453-6.

14. Ishikura H, Kishimoto T, Andachi H, Kakuta Y, Yoshiki T. Gastrointestinal hepatoid adenocarcinoma: venous permeation and mimicry of hepatocellular carcinoma, a report of four cases. Histopathology. 1997:31:47-54

15. Lattes C, Carella R, Faggioli S, Gabusi E, Grigioni WF. Hepatoid adenocarcinoma of the rectum arising in ulcerative colitis: report of a case. Dis Colon Rectum. 2000;43:105-8.
16. Yachida S, Fukushima N, Nakanishi Y, Akasu T, Kitamura H, Sakamoto M, et al. Alpha-fetoprotein-producing carcinoma of the colon: report of a case and review of the literature. Dis Colon Rectum. 2003;46:826-31.

17. Fu K, Kobayashi A, Saito N, Sano Y, Kato S, Ikematsu H, et al. Alpha-fetoproteinproducing colon cancer with atypical bulky lymph node metastasis. World J Gastroenterol. 2006;12:7715-6.

18. Nakagawa K, Koike S, Matsumura H, Yokoi K. Kitamura H [alpha-fetoprotein producing rectal cancer]. Gan To Kagaku Ryoho. 2012;39:671-4.

19. Shiwaku H. Alpha-fetoprotein producing carcinoma of sigmoid colon; [article in Japanese]. Jpn Gastroenterol Surg. 2007;40:134-40.

20. Hishinuma M, Ohashi Kl, Yamauchi N, Kashima T, Uozaki H, Ota S, et al. Hepatocellular oncofetal protein, glypican 3 is a sensitive marker for alpha-fetoprotein-producing gastric carcinoma. Histopathology. 2006;49:479-86.

21. Kitajima K, Fujimori T, Fujii S, Takeda J, Ohkura Y, Kawamata H, et al. Correlations between lymph node metastasis and depth of submucosal invasion in submucosal invasive colorectal carcinoma: a Japanese collaborative study. J Gastroenterol. 2004;39:534-43.

22. Netzer P, Forster C, Biral R, Ruchti C, Neuweiler J, Stauffer E, et al. Risk factor assessment of endoscopically removed malignant colorectal polyps. Gut. 1998:43:669-74.

23. Seitz U, Bohnacker S, Seewald S, Thonke F, Brand B, Braiutigam T, et al. Is endoscopic polypectomy an adequate therapy for malignant colorectal adenomas? Presentation of 114 patients and review of the literature. Dis Colon Rectum. 2004;47:1789-96. discussion 1796-1787.

24. Yasuda K, Inomata M, Shiromizu A, Shiraishi N, Higashi H, Kitano S. Risk factors for occult lymph node metastasis of colorectal cancer invading the submucosa and indications for endoscopic mucosal resection. Dis Colon Rectum. 2007;50:1370-6.

\section{Submit your next manuscript to BioMed Central and take full advantage of:}

- Convenient online submission

- Thorough peer review

- No space constraints or color figure charges

- Immediate publication on acceptance

- Inclusion in PubMed, CAS, Scopus and Google Scholar

- Research which is freely available for redistribution 